\title{
Reputation: Some Thoughts From An Investor's Point of View"
}

\author{
Stefan Schürmann \\ Credit Agricole Cheuvreux, Bahnhofstrasse 18, Zurich 8001, Switzerland. \\ E-mail: sschuermann@cheuvreux.com
}

The author describes the reputation of the insurance industry in Europe from an investor's angle. In the first part, he argues that the industry has suffered from a bad reputation in recent years, driven by "negative" events such as WTC, pension mis-selling or the U.S. Spitzer investigations. A changing framework, such as Solvency II, and the industry's increased awareness of the importance of reputation contribute to a better picture for the industry. The author elaborates on a changing industry from different stakeholder viewpoints. In the second part, he explains the results of a small survey conducted among 10 major European investors in insurance stocks. The main finding is that investors' valuation models do not explicitly deal with reputation. However, reputation does matter for investment decisions and the main factors influencing reputation from an investor's angle are "management" and "communication".

The Geneva Papers (2006) 31, 454-469. doi:10.1057/palgrave.gpp.2510094

Keywords: reputation management; measuring reputation; insurance industry; insurance valuation; European insurance

\section{General analysis of reputation in European insurance industry}

\section{Definition of reputation}

A possible definition of reputation ${ }^{1}$ is "the general opinion (or social evaluation) of the public towards a person, group of people, or an organisation". It is important to note that reputation is a dynamic phenomenon that is subject to change. In the case of an insurance company, accounting errors, overpromising of results, management corruption or poor communication can be negative issues for reputation. For restoring a damaged reputation, time can heal all ills, but a more effective and promising approach is intense stakeholder interaction on all levels. It can be argued that reputation is a top management issue, and may be one of the most important tasks and challenges facing management today.

A more specific definition for the insurance industry can be taken from the U.K. regulatory body, the FSA, which defines reputational risk as "the risk that the firm may be exposed to negative publicity about its business practices or internal controls, which could have an impact on the liquidity or capital of the firm, or cause a change in its credit rating". 2

\footnotetext{
* This article reflects the author's personal opinion.

${ }^{1}$ Source: Wikipedia online encyclopaedia.

${ }^{2}$ Source: FSA (2005).
} 


\section{Image and reputation}

Before continuing with this part, it must be stressed that there is a difference between the terms "image" and "reputation". Whereas image is rather a belief or evaluation (of an organization), reputation is a meta-belief or a belief based on others' evaluations (of an institution). This difference means that reputation is more anonymous, whereas image is more tied to a subject. In stock market terms, one can have a positive image of an insurance company since my insurance agent is a great person offering the services needed, but the company's reputation is bad because of accounting problems or management scandals. If the image of this company is or becomes positive, then we have a chance of seeing an improvement in its reputation over time. This means that reputation evolves more slowly than image.

\section{Measuring reputation}

The most difficult issue is to measure the value of reputation or its loss. In fact, a company's stock market valuation is influenced by multiple factors, and it is not an easy task to measure such an impact. We do not have many existing examples. One example that could be used here is Coca Cola, which according to its own estimates lost USD60bn after schoolchildren reported suffering from symptoms such as headaches, nausea and shivering after drinking its products. ${ }^{3}$

Whereas the question of measuring reputation is thoroughly discussed by some insurance companies, eager to find a magic formula to insure "reputation" as a risk class, there is not much of a widespread accepted framework available to measure such an intangible issue for the insurance industry itself.

Reputation could be defined as the value of a brand, but also as the "emotional capital, of an organization. The value of the brand can then be determined by consulting companies measuring people's perceptions of the brand. In addition, for quoted companies, the value of the brand can be the stock market value minus the book value, but this only results in a "point" estimate at a certain time. A company called CoreBrand uses a methodology of combining survey-based "favourability" ratings and financial analysis to estimate brand value. On average, for the general industry, such brand value was indicated at 5-7 per cent of market capitalization in 2005 (today, this value would certainly be higher). ${ }^{4}$

\section{Reputation more than just brand value}

It would be trivial to put everything down to "brand" value. Reputation is certainly more than brand. Brand is more the marketing-based element, whereas reputation includes a broader range of soft elements, which could be described as emotional capital. This might include corporate governance or a company's policy on socially and ethically sound behaviour. In today's investment community, it is possible to discern a trend towards SRI (socially responsible investments) which is likely to further increase the focus on soft issues such as reputation.

\footnotetext{
${ }^{3}$ Source: ZFS (2004)

${ }^{4}$ Source: Harris (2004).
} 
To measure brand or emotional capital, we would need a long data series, covering more than one stock market or the non-life insurance cycle. The results would be a very volatile valuation of these elements, as markets always tend to over/underestimate the underlying reality. This by the way is the basis for cycles, which are driven by investors' psychology, and may be the most important reason for justifying the existence of the analyst community.

\section{Measuring a negative reputation impact}

The NYAG and SEC enquiries into accounting fraud at AIG led to the devaluation of the biggest insurance company - measured by market capitalization - of the last decade. The issue included the use of financial reinsurance. Not much is fundamentally wrong with financial (re)insurance, but the lack of a clear definition of "Finite Re" and the inability of the industry to deal with the issue led to negative publicity, which is not entirely over yet. Fundamentally, most of the financial reinsurance was used to smooth the returns of a long-term business in order to avoid somewhat artificial volatility that is due to the inability of the accounting framework to reflect underlying earnings trends.

In the case of AIG and the recent and still ongoing SEC and NYAG investigations, when taking the share price drop from the moment of the announcement in March 2005 and the settlement of the USD1.64bn fine in February 2006, we saw a share value destruction of almost USD10bn in absolute terms by today's standards (including a market value loss of USD8bn). The stock is still trading below the USD66 level it was at before the announcement of the Spitzer issue at the time of this writing. When adjusting for the U.S. insurance market sector performance over the last 12 months, the relative damage is closer to USD40bn. This is a better estimate of the cost of loss of reputation in this case, measured after 1 year.

It appears that AIG did not have a groupwide "reputation recovery" plan in place to limit the damage. All that happened was that the new CEO invested a lot of time sitting down with interested parties (mostly the press and investors) to discuss the issue. As of today, it can be said that the situation has calmed down but is still in people's minds somewhere, as AIG's previously impressive position - when it was perceived as the world's leading, rock-solid insurance company by far - seems to be damaged and will take time to be restored, if at all. Therefore, we believe the damage from a loss of reputation is not yet over and is still showing signs a year later. Interestingly, it is said that AIG has now set up a committee at management level to deal with the issue of reputation.

\section{Good or bad reputation of the insurance industry}

Negative publicity overwhelms

We believe the negative publicity over the last few years masks the underlying improvements in the industry. Recent negative publicity started with the WTC event in September 2001, where the industry was presented as an unreliable contract partner, employed against itself by the U.S. legal "machine". The press discussed this topic over a period of months, and it was negative for the industry's reputation. 


\section{Failure of insurers}

Early in the new millennium, low interest rates coupled with continuously falling stock markets led to bankruptcies, mostly in Japan, Europe and Australia, with a large number of companies going through severe crises, including capital increases and management changes. Here again, the press played an important role firing up adverse publicity for the sector.

\section{Pension mis-selling}

We also had pension mis-selling, which was most pronounced in the U.K. In fact, the expected future return by life insurance savings products was negatively impacted by difficult financial markets. Other industries such as private banking handled the issue far better, by offering compensation to complaining clients, thereby avoiding legal action. Only very recently have sales volumes picked up again.

\section{Bid rigging}

Another case is bid rigging in the U.S. insurance industry, where some wrongdoing might have been involved. However, how is it possible that companies such as Zurich Financial Services are ready to pay USD $325 \mathrm{~m}$ ? It is all down to reputation. In fact, the faster negative news is dealt with and resolved, the better for reputation.

\section{Sustained gain in reputation}

When looking at why (U.S.) insurers went bankrupt over a period of 10 years to 2002 (Figure 1), we can see that deficient loss reserves was the most frequent reason. The author believes that the new solvency framework being installed in Europe should

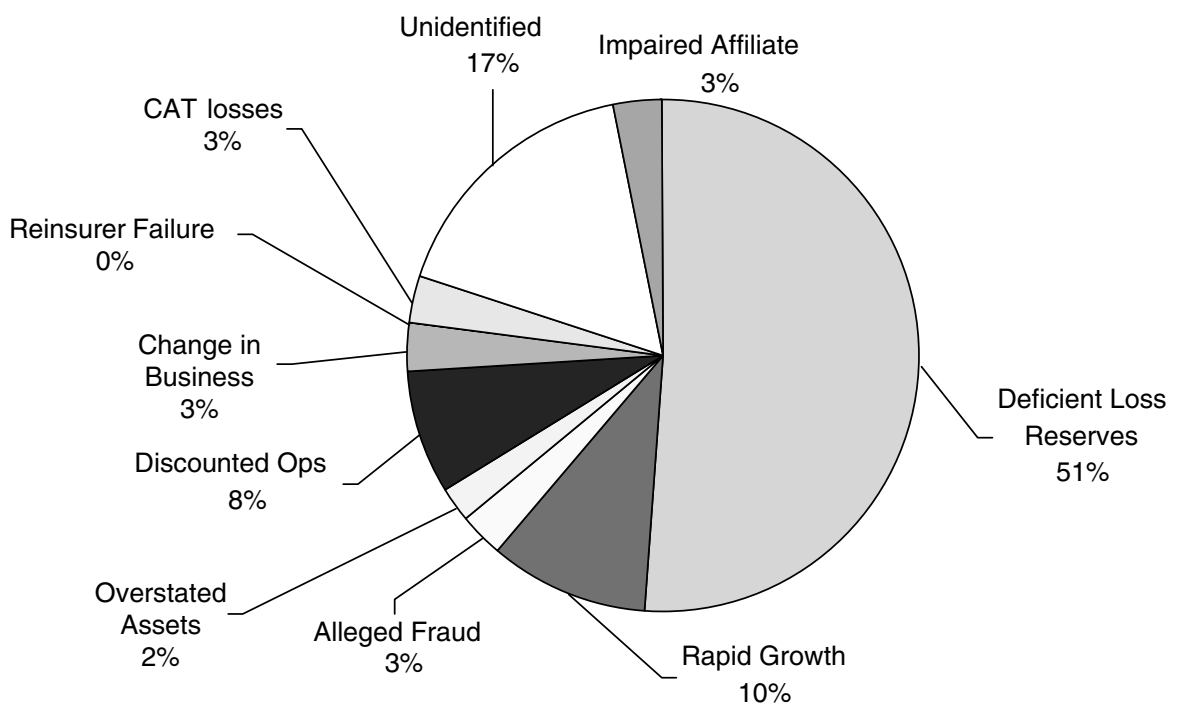

Figure 1. U.S. 218 insurance failures 1993-2002, non-life industry. Source: AM Best, III. 
create a better understanding for each insurance company of the risks taken on its balance sheet. The big challenge is not to find a fair value accounting framework, but to find a way of adequately measuring liabilities, including sufficient, but not excessive, prudence. We should learn from history and not reinvent the wheel.

It appears that insurers are currently going through a similar development to the U.S. banks in the 1980s and early 1990s. During the period 1980-1993, 2,500 banks and savings institutions were swept away in the U.S. Deregulation in the 1970s and 1980 s led to massive industry expansion without a rise in risk-management capabilities. The wave peaked in 1991 when 124 banks with USD53.75bn in assets failed. ${ }^{5}$ Failures were mostly due to mismanagement and fraud. However, the industry learned its lesson. Increased government regulation, competitive pressures and improved risk-management reduced the chance of large-scale bank failures. From 1997 to 2005, only 36 banks with combined assets of about USD5.15bn have failed. ${ }^{6}$ It is clear that the insurance industry is now also entering a phase of improved risk-based management that will lead to a better perception of the sector, which will be seen less in terms of failures, but in terms of profitability and understanding from the outside offering the prospect of a sustainable gain in reputation.

Banks advantaged over insurers?

An interesting point in the newly discussed Solvency II framework in Europe is the amount of capital allocated for each investment class. When looking at the proposals in different countries, we can see a more conservative treatment for insurance companies than for banks. For example, the German GDV/BAFIN shows theamount of risk capital required for different asset classes (as a percentage of assets) (Table 1). ${ }^{7}$

A look at this comparative table suggests there is a risk that today's picture of the insurance industry underperforming the banking sector will prevail. ROEs over the next few years are expected to be much lower for the insurers than for banks, as the Basel II framework overall allowed for better and often higher risk taking for banks, so that both result in lower capital tied to the model and higher returns on the capital invested due to the higher risk component.

In terms of reputation, the important issue is that in a market with a broad and longstanding history of shareholdings by the public, sustained higher ROEs bring a better reputation for quoted companies. This obviously depends on the country's

Table 1 Amount of risk capital required for different asset classes

\begin{tabular}{lcr}
\hline Solvency II & GDV model 2005 & Basel II \\
\hline Fixed income AA & $2.7-6.2$ & $0.225-4.35$ \\
Fixed income BBB & $9.0-12.5$ & $0.475-4.35$ \\
Equity (unsecured) & 31.8 & $12.0-16.0$ \\
Equity (secured at 20 per cent) & 20.0 & $5.6-9.6$ \\
\hline
\end{tabular}

\footnotetext{
5 Source: FDIC (1991).

${ }^{6}$ Source: Ibid.

${ }^{7} \mathrm{GDV}$, amendment to the Capital Accord to incorporated market risks; Basel Committee (2005); McKinsey.
} 
culture, but companies with high returns in recent years are usually to be found high up in reputation surveys in the U.S. In Europe, this is somewhat different but has also gained in importance over the last decade.

\section{Solvency II should motivate to take measured risks}

Therefore, we do not share the view of a "prudent" framework for Solvency II. On the contrary, the framework should not set the level of target capital too high and should allow the use of risky asset classes in the derivatives segments, alternative asset classes and emerging markets. These asset classes will help to deliver a superior return over other assets in the long run.

However, the Solvency II framework should ensure that an insurance company is fully aware of the risks taken on the asset side, preferably on a daily basis. Moreover, the regulatory framework should motivate insurers to either manage these assets inhouse, or if quality standards cannot be met, to outsource them to third parties without any penalty for solvency reasons.

\section{ROE focus versus policyholder protection}

Assuming that a good ROE performance is improving the reputation of a specific company or the entire industry, there is a danger that policyholder protection will threaten such improvements in the next few years. Risk-based regulation has a tendency to motivate insurance companies into risk-averse investments likely to reduce long-term earnings potential. Moreover, it might take away some of the long-term business model appeal (long-tail business requiring high asset underlyings), which allowed the industry to have a high "float", as Warren Buffet names assets brought in by policyholders. The new framework could cause a capacity shortage in areas such as catastrophe retrocession and pandemic risk protection. The old question of the role of the private insurance industry compared with public institutions and the ability of the industry to provide the coverage society needs will come up again and have an impact on the reputation of the industry.

\section{Changing reputation takes a long time}

Changing the reputation of an industry takes a long time and sustained interaction with all levels of stakeholders. For an insurance company, a social evaluation or general opinion is shaped by all the stakeholders outlined in Figure 2. We will therefore have a brief look at the viewpoint of the various players that have an influence on an insurance company's reputation.

\section{Employees}

Would you work for an insurance company?

Starting with a very important asset of an insurance company, its employees, we try to elaborate on the impact of reputation on their behaviour. In the public's eye, the archetypal image of a typical insurance employee is still either the bureaucratic, 9-to-5-o'clock administrative role or the image of a "crook" of an insurance agent hard-selling an insurance policy, even though coverage is mandatory anyway, and where it is impossible to compare the same policy coverage from another insurance company. 


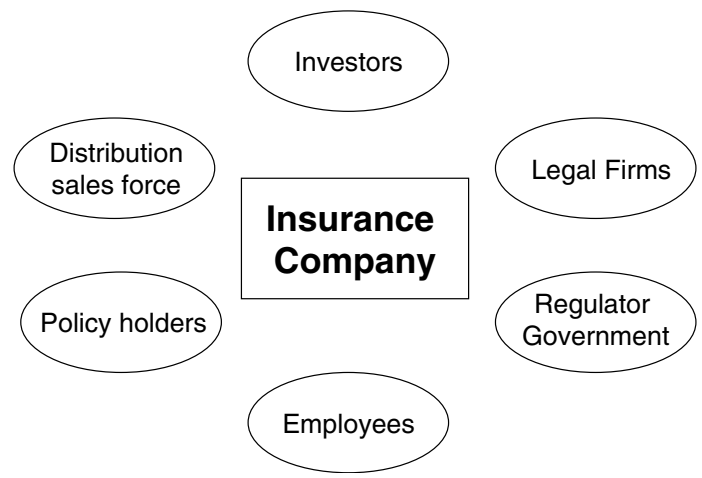

Figure 2. Stakeholders and their view of the industry.

Industry is changing

Another old image is depicted in Monty Python's The Meaning of Life where the insurance company is portrayed as a battleship conquering the New World: a crowd of nearly retired male employees are labouring over mountains of paperwork while supervisors act as slavedrivers, in a parody of the old Lloyds Market. This image was far more realistic 10 years ago than we would like to believe today: processes, job requirements and therefore employment activities are changing in this industry.

Many highly qualified mathematical, IT, accounting, marketing, legal and financial specialists were hired over the last few years. This was caused by the banking industry's consolidation, which saw a flow of talent moving into the insurance industry in the last decade.

We can now raise the question of hiring talent for the insurance industry. Is someone who holds a university degree and is eager to start their career more willing to be employed in the insurance industry or in other sectors such as food, pharmaceuticals or banking? In our experience, a person who has a choice, with similar levels of compensation being offered, usually decides against the insurance industry. This reflects the comparatively low reputation of this industry. However, here again, we do see some change for the better.

Improved and sustained higher profitability (in ROE terms) would be a positive factor for the industry's attraction, which would make it easier for insurance companies to attract talent.

\section{Policyholders}

Does any policyholder know its exact insurance coverage?

The other single most important stakeholders are clients. During our discussions with various people on the issue of reputation, we heard comments such as "I would never buy a savings product from a life insurance company". This clearly reflects the life insurance industry's failure to convince potential policyholders of its asset management capacity. However, investment funds run by insurance companies do not generally underperform bank-owned funds: it is just down to reputation and perhaps marketing. 
Another comment that has stayed with me came from a regulator at an international insurance seminar who told the audience that he had to motivate himself hard to go through the homeowner's policy in order to explain to his wife what exactly their coverage was. This example shows that the problem of insurance is a profound one and has to do with its opaqueness. Accounts are not as easy to read as in banking, which explains the wealth situation in one single figure (positive view: what is "included"). Insurance contracts include a list of events covered and another list of events excluded (negative view: what is "excluded"), including the policyholder conditions, which on their own are often a challenging document to decipher.

The main arena for improving the industry's long-term reputation lies here. Insurers should aim to establish a clear and transparent set of coverage details, which might include "what if" situations summarizing insurance coverage for a specific and "typical" claims event. In the age of space travel to Mars, it should be possible to draw up insurance contracts that are easy to read, clear and understandable for the average human being. Furthermore, why not explain in advertising spots, as an educational tool, what a typical insurance policy does cover? Or what does a claims handling process look like? And most important, what about showing happy clients after a claims payment? There is significant room for improvement here.

\section{Regulator/government}

Regulators are interested in the insurance industry having a good reputation, but it is not their primary concern. Their primary concern is to protect policyholders. Therefore, their work is often to provide a set of solvency rules that ensure the survival of an insurance company in the long run. Should an insurer find itself in financial difficulties, regulators may intervene and resolve the situation by implementing measures. The challenge of regulation, in my view, is to leave the industry enough freedom to create an interesting, innovative and competitive market, while ensuring the financial stability of the companies in the long run.

\section{Legal firms}

Although not an obvious stakeholder, "legal" stakeholders are increasingly important in the insurance industry, and this article therefore places special emphasis on them.

The reason we bring up lawyers as stakeholders is mostly because the U.S. class action lawsuits over the last few years, in issues such as asbestos, have seen the insurance industry as an easy target for backdated claims payments to policyholders suffering from real and/or potential health problems. In this process, the legal industry earns a good deal of the total payments, which in 2004 amounted to USD262bn, according to the Insurance Information Institute. The real problem is that the industry feeds itself with such actions, as only 22 per cent of the total amount counts as "award for economic loss" (Figure 3).

An example is the WTC claims process, which is still ongoing between the insurance industry and owners of damaged property, where contract uncertainty is used by a legal firm to chase up punitive claims payments. 


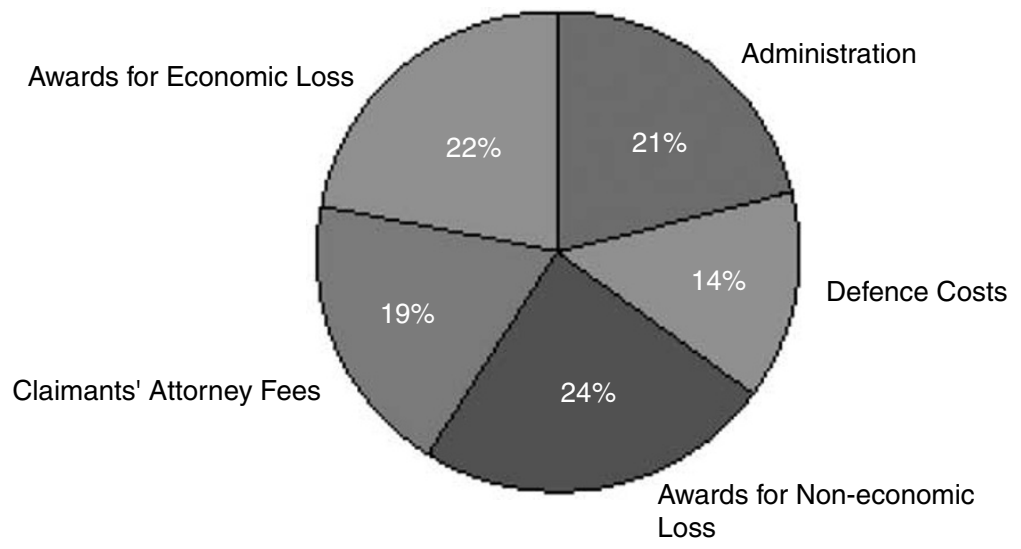

Figure 3. Class Action lawsuit payout distribution. Source: Insurance Information Institute.

Another issue is the SEC/Spitzer enquiry into accounting fraud in regard to financial reinsurance, where once again big fines are paid and the size of lawyers' fees often come close to that of the "fined" amount.

In all these issues, legal firms have to be considered as influential parties in the interaction with insurance companies and their environment; this is close to the role of a stakeholder, making a profit on reputation issues that have not been priced into insurance products at the time of sale.

\section{Proactive and rapid action required}

The industry has started to recognize that in this issue, proactive, rapid and determined action is important to reduce pecuniary damage. We are seeing such issues being handled by top management, actions which are improving the situation and starting to make the industry less vulnerable to its "predators".

However, the recent hurricane Katrina catastrophe shows that legal issues are not off the table yet. In fact, accusations are being made against insurers by trial lawyers or the Mississippi Attorney General Jim Hood, as highlighted in the following points (to mention just a few):

- violation of the public policy of the State of Mississippi; alleges flood exclusion is void since law does not allow exclusions that interfere with proximate cause;

- unconscionability: contracts are unreasonably complex;

- water damage and/or flood exclusions are ambiguous.

These accusations are not quite understandable from a legal point of view, as flood coverage is excluded in U.S. homeowner's policies and has been for the past 40 years. However, there is a real risk that these rulings against insurers could go through, which would set a dangerous precedent of contract abrogation. 


\section{Legal issues remain a major threat}

In conclusion, the impact of the legal industry is not increasing in the general industry in the U.S., with total cases being on the decrease. In 2005, only 181 shareholder class action lawsuits were filed compared with 497 in 2001 or 272 in $2002 .{ }^{8}$ This is also reflected in lower charges for the U.S. insurance industry recently. However, legal issues are starting to pick up in Europe and therefore remain a threat for the insurance industry overall. The only way for the industry to prevent legal action in the future is through contract certainty.

\section{Distribution}

This issue brings us to the next stakeholder category in the insurance industry: distributors of insurance products. Today, insurance policies are written through tied agents or the company's own sales force and brokers/financial advisors, but selling via banks, the internet or direct telephone sales is also gaining in importance.

\section{Contract certainty an important step forward}

"Contract certainty" is starting to be a major issue, especially in broker distribution for commercial insurance coverage. Whereas a few years ago the usual procedure was a handshake or a phone call to renew premiums and conditions between the two parties, we are now entering a phase of better clarity on coverage and on the timing of the start of coverage. The Lloyds market has set a target for 85 per cent of all monthly volumes to be "contract certain" by end-2006. ${ }^{9}$ This means that the full wording must be agreed before any insurer formally commits to the contracts and appropriate evidence of cover is to be issued within 30 days of inception. We see this as a great step forward for the reputation of the industry, which was or still is in legal battles over how to pay for the WTC event back in 2001. We expect the new contract certainty to reduce the scope for legal disputes and we also expect Lloyd's reform to spread to the global commercial insurance market. The impact will not be felt immediately, but it should have a sustained positive effect over the next few years, helping the reputation of the insurance industry at large.

\section{Greater sophistication in underwriting}

Furthermore, distribution is starting to feel the impact of risk-based models, which allocate capital differently towards certain lines of business than 5 years ago. This process has only just started and has taken away some of the freedom of the underwriter/seller of an insurance product (especially in business-to-business lines). However, over time the distribution force is likely to accept a healthier process where unreasonable pricing should no longer be as widespread as in the past - to the benefit of the insurance industry's overall reputation.

\footnotetext{
${ }^{8}$ Source: Hartwig (2006)

${ }^{9}$ Source: Market Reform Programme Office (2005).
} 


\section{Shareholders/investors}

Reputation from a shareholder's angle

This paper's primary objective is to elaborate on reputation from an investor's angle. We will therefore focus in the second part of this article on the shareholder's perspectives.

\section{Investors' views on the reputation of the European insurance sector}

\section{Investor survey}

The view of investors obviously has an important impact on the total reputation of a company. As a financial analyst talking to this community, we have a certain picture of what investors think of the subject. However, we wanted to go into more detail than just a "feeling" and therefore conducted a very small (and statistically insignificant) survey of major European investors. We interviewed 10 experienced buy side analysts and/or portfolio managers specializing in the financial sector, from the biggest institutional investors in Europe, based in London, Paris and Zürich. Some investors asked to remain anonymous, which we fully respect. We estimate that these investors have an average of around 15 years' experience of working in the insurance/financial sector, which in my view demonstrates their thorough knowledge of the European insurance sector. Taken together, these institutions manage well over USD1,500bn of institutional money and have an influential opinion on financial stocks. Therefore, we could expect an expert "investor's" opinion on the subject.

\section{Do you care about reputation?}

The first question was “Do you care about a company's reputation in your investment decision?" (Table 2).

Only one respondent started with a "no", arguing that most badly rated companies can offer the best potential for stock performance. Most investors answered that "yes they do care", but that reputation was an intangible issue that could not be measured in their models. Also, more than one answer pointed out that reputation would impact reported figures and therefore valuation over time. One investor explained that if the management rating (which reflects reputation to them) differed from the statistical mean, then reputation has an influence on the investment decision. One investor mentioned that reputation only marginally influenced the investment decision and another one said that reputation would impact the "gut feeling".

Table 2 Investor survey, first question

Do you care about reputation in your investment decision?

$\begin{array}{ll}\text { No } & 10 \text { per cent } \\ \text { Only partially } & 50 \text { per cent } \\ \text { Yes } & 40 \text { per cent }\end{array}$




\section{Reputation reflected in numbers over time}

Overall, it appears that there is no clearly defined process to include reputation as an element in the investment decision process. However, there is no evidence either that reputation does not matter. The interviews were conducted during cold calls, which left respondents no time for preparation.

The answers are understandable as number crunching uses up most of the time available and soft elements therefore tend to be neglected. The very challenging measuring framework, consisting of a difficulty to use IFRS accounting system for the insurance industry, a European embedded value framework that is currently becoming rather more subjective than consistent and a changing solvency environment, does not leave much time for soft factors such as reputation.

\section{An intangible issue}

The second question "Do you give credit/premium for reputation in your valuation model?" was more precise.

Some said that reputation was too intangible to be measured. One answer was that stocks were generally split into treasury stocks and "non-treasury" stocks, which in the first instance means long-term core holdings and in the latter only trading opportunities. The definition of "treasury stocks" is simple: the companies with a good reputation. Another investor said a price to net asset value (or embedded value) multiple below 1 reflected a bad reputation, while a valuation above $1 \times$ would imply a good reputation. This is a very interesting and at the same time obvious observation. In a prospective view, this would suggest that reputation is very important for insurance companies' valuations, as reputation must first improve before valuation does. In our view, the perception of a stock price is influenced by reputation, and therefore reputation has an impact on valuation. Another investor said that reputation influenced valuation estimates. We think this statement might be true for every investor, be it consciously or unconsciously. An interesting answer came from one investor who said that trust in management impacted the risk discount rate and therefore the weighted average cost of capital (WACC) in the valuation model. This appears to me to be the easiest and most evident way to include a soft factor such as reputation in a valuation model.

The third question was "What are the factors you look at in terms of reputation"? (Table 3).

Here, many investors answered "management": management credibility, management track record, management assessment and trust in management. Other factors driving reputation for an investor are corporate communication and trustworthiness. "Telling the truth all the time is quite simple" was the valuable statement of one investor.

\section{Management is impacting reputation}

There is no clear perception of what reputation really means, but most link it with management behaviour and/or communication. This is very interesting and suggests 
The Geneva Papers on Risk and Insurance - Issues and Practice

466

Table 3 Investor survey, question three

What factors influence reputation?

Number of answers

Management

Reserves/pricing/exposure/claims payment

6

Balance sheet strength

Corporate communication

3

Truth, honesty of management/communication

Client loyalty

Delivering on promises

6
3
2
2
2
1
1

Table 4 Investor survey, question four

Insurance industry's rating? (1-10)

Today (average score)

6.3

3 years ago

Today better/much better

that in order to improve a company's reputation, management of an insurance company has to excel in honest, transparent and consistent communication to investors. This also suggests that management's compensation could and should depend on their communication skills with investors.

Question number four was "what is the insurance industry's reputation" on a scale of 1 (bad) to 10 (excellent)? (Table 4).

Interestingly, the average rating came in at 6.3 points, with 4 being the worst and 7.5 the highest rating. This shows that the industry has room for improvement in terms of reputation assessment by investors, but also that the current reputation is not bad.

\section{Reputation is improving}

The add-on question was an easy one and investigated the difference between the situation today and the situation 3 years ago. Since the industry was in the midst of a stock market depression in 2003, all the respondents answered "better" or "much better". One answer was that 3 years ago, a " 2 " rating would have been adequate: therefore, clearly an improving picture.

We now turn to the most sensitive part of the survey. In fact, not all answered the question "which companies have the best/worst reputation"?

These investors are mainly focused on Europe and the results should be viewed cautiously.

In fact, we asked them to indicate two, three or more companies with a good reputation and the same number with a bad reputation (Table 5).

\section{Correlation between stock performance and reputation?}

The striking issue is that Axa was mentioned as having a good reputation by most investors. ING, Allianz and ZFS also got more than one vote, with Allianz and ZFS 
Table 5 Investor survey, question five

\begin{tabular}{lcr}
\hline Company's reputation survey & Good & Bad \\
\hline AEGON & 7 & 3 \\
Axa & 1 & \\
Aviva & 3 & 1 \\
Allianz & 1 & 3 \\
Baloise & 1 & \\
Converium & 1 & 1 \\
Friends Provident & 3 & 2 \\
Generali & 1 & 4 \\
ING & & \\
Irish Life & & \\
Mediolanum & 1 & \\
Prudential & & \\
Skandia & 1 & \\
Swiss Re & 2 & \\
Topdanmark & & \\
ZFS & & \\
\hline
\end{tabular}

mentioned a few times as having improved their reputation the most. Interestingly, and to the best of our knowledge, Axa and more recently Allianz and ZFS have initiated reputation management programmes, being among the leaders in this regard in the European insurance industry. However, again, these results are not statistically meaningful and only indicative.

Nevertheless, the stock price valuation of the companies mentioned under "good reputation" increased by 34 per cent ${ }^{10}$ over the last 12 months for Axa and ING, by 37 per cent for Allianz and by 41 per cent for ZFS, compared with 30 per cent for the European insurance sector over the same time frame. While a view of 12 months back may not be meaningful, it reflects the view collected from this group of investors.

On the other hand, what surprised us was that the worst performer, Swiss Re, has also underperformed the market over the last 2 to 3 years. Only Generali, AEGON and Prudential received more than one negative vote. Looking back 12 months, Swiss Re performed by 13 per cent, Generali by 17 per cent and Prudential by 29 per cent, with AEGON being the exception, performing better than the sector at 39 per cent. Here again, with the exception of AEGON and Prudential being in line, the view indicated by these big investors could justify the recent stock price performance. It would be worth a more detailed and in-depth study in order to find statistically meaningful results.

The last question relating to the table above was "why do you think the reputation is good or bad"?

Here the answers were diverse and again showed that there exists no clear definition of the reputation of an insurance company among investors. Management quality, communication to investors, transparency, confidence, capital optimization, pricing

\footnotetext{
${ }^{10}$ Based on the data from end of April 2006.
} 
The Geneva Papers on Risk and Insurance - Issues and Practice

468

discipline and product design, innovation and consistency of delivery were mentioned as reasons for their assessment of a good or bad reputation in the discussion.

\section{Management and communication as main reputation drivers}

It appears again that management and communication are currently the driving forces of the reputation assessment. This suggests that management has to be trained for the communication function and that communication is one the most important functions in an (insurance) company.

Moreover, the demand for more transparency and better data consistency highlights the lack of an easy to understand and easy to control measurement system for the insurance industry. As long as underlying company developments are not reflected through a sensible reporting system, communication can be perfect but still fail to impact reputation.

\section{Conclusion}

\section{Reputation is improving}

This survey and general discussions and observations with investors in insurance stocks around the world show that that reputation of the insurance industry is improving, although no specific valuation framework exists to measure this impact in valuation models. The ability of each investor to include his view of the reputation of an insurance company is obviously limited in terms of broadness and reach and mostly geared towards management meetings, which usually take place between one and four times per year.

\section{Reputation management in the early stage}

The industry is working on reputation and we believe investors' perceptions will be influenced by this work. However, as often, reputation changes among the wider public will take time. Higher share prices should help. Owing to stock markets rises in Europe over the last 3 years, we can already see a great improvement, but only a negative stock market correction will tell us how resistant this green shoot really is.

\section{Industry should reinforce lobbying on future framework}

On a wider view, IFRS Phase II, European embedded value (EEV) and Solvency II are all developing frameworks, mostly for the good but still taking too long to be implemented. In addition, the potential political influence on IFRS Phase II and the so far modest lobbying from insurance companies and the investment community on this future framework is somewhat worrying.

EEV is an improvement, but is proving a smaller and slower process than expected. Moreover, increasingly subjective elements are being used in recent disclosure to bias the new EEV figures towards the old traditional EV figures, without real consistency 
between insurance companies being achieved yet. Nevertheless, the EEV framework is a positive step for the insurance industry's reputation.

Solvency II appears to be on track for a fairly reasonable framework, but it is too early to tell. A regulatory tightening is likely and also includes some risks. The real issue here is that too much policyholder protection could have a negative impact on the industry's reputation.

If we compare reputation to a tree, then we can say that its roots have grown deeper and wider over the last few years, but they must grow still further if they are to withstand future windstorms.

\section{References}

Basel Committee on Banking Supervision (2005) Amendment to the Capital Accord to Incorporate Market Risks, Basel: BIS (November).

Harris, F. (2004) 'Picking Up The Pieces', CFO Magazine, August.

Hartwig, R. (2006) Property/Casualty Insurance Financial \& Hurricane Update, taken from http:// www.iii.org/media/presentations/financialhurricaneupdate/.

Federal Deposit Insurance Corporation (1991) Bank Failures and Assistance Chief Economist Richard Brown, FDIC, http://www.fdic.gov/bank/historical/bank/1991/index.html.

Financial Services Authority (2001) Integrated Prudential Source Book, London: FSA.

Market Reform Programme Office (2001) Contract Certainty Code of Practice, London: Society of Lloyd's (October).

Zurich Financial Services (2004) 'The fragile world of company reputations', Industry Insight (June), from http://www.zurich.com/main/productsandsolutions/industryinsight/2004/june2004/industryinsight20040603_003.htm.

\section{About the Author}

Stefan Schuermann is an Insurance Analyst at Credit Agricole Cheuvreux in Zurich. 